\title{
Gestão Estratégica com Responsabilidade Social: Arcabouço Analítico para Auxiliar sua Implementação em Empresas no Brasil
}

\author{
Renata Buarque Goulart Coutinho \\ T. Diana L. v. A. Macedo-Soares
}

\section{Resumo}

Seguindo uma tendência mundial, as empresas no Brasil estão cada vez mais preocupadas com a responsabilidade social. Sendo assim, passam a contemplar mudanças organizacionais de implicações estratégicas profundas. Parte-se da premissa de que, para serem efetivas, tais mudanças devem estar alinhadas com a estratégia de negócios da empresa. O objetivo deste artigo é compartilhar os resultados de pesquisa bibliográfica e documental nas áreas de negócios e sociedade e gestão estratégica, com vistas a desenvolver um conjunto de ferramentas conceituais que possa auxiliar na formulação e implementação mais eficaz de estratégias de negócios direcionadas à responsabilidade social, no contexto brasileiro. Primeiro apresenta-se o arcabouço analítico em questão, construído por meio da síntese de elementos pertinentes de ambas as áreas de conhecimento. Depois, fornecese um exemplo de como este pode ser utilizado para auxiliar a análise das mudanças a serem realizadas, a fim de que as práticas de responsabilidade social estejam alinhadas com a estratégia de negócios da empresa e, desta forma, possam contribuir para sua efetividade.

Palavras-chaves: responsabilidade social corporativa; cidadania empresarial; gestão estratégica; adequação estratégica.

\section{Abstract}

As elsewhere in the world, firms in Brazil are increasingly concerned with social responsibility. Thus, organizational changes are being contemplated that have profound strategic implications. It is assumed here that, to be effective, such changes should be aligned with the firm's business strategy. The objective of this article is to share the results of extensive bibliographical and documentary research, in the fields of business and society and strategy management, with a view to enhancing the chances of success with development and implementation, in the Brazilian context, of social responsibility-oriented business strategies. It presents a set of conceptual tools that was constructed or adapted on the basis of a synthesis of pertinent elements from both the strategy and social responsibility literature. An example is given of how these tools can be used to help analyze which changes should be carried out, so as to ensure that the key practices for becoming a socially responsible firm are aligned with its business strategy, and thus contribute to its effectiveness.

Key words: corporate social responsibility; corporate citizenship; strategic management; strategic fit. 


\section{INTRODUÇÃO}

Devido ao agravamento de problemas sociais e ambientais por todo o planeta desemprego, exclusão, poluição, exaustão de recursos naturais - e à dificuldade dos governos de solucioná-los, as forças da sociedade estão passando por um processo de reorganização. É neste contexto que as empresas sentem a pressão para adotarem uma postura socialmente responsável na condução dos seus negócios.

As empresas conscientizam-se, assim, da importância de considerar os interesses de outros grupos, não só dos acionistas, afetados por sua atuação: fornecedores, empregados, comunidade, consumidores, sociedade e meio ambiente. A própria noção de sucesso empresarial está sendo questionada, trocando-se o pano de fundo dos resultados apenas econômicos para um cenário que exige resultados também sociais e ambientais, dentro de uma perspectiva de desenvolvimento sustentável (Maynard e Mehrtens, 1993; Frederick, 1994; Clarkson, 1995).

Descobre-se a dimensão estratégica da responsabilidade social, na medida em que ela possa contribuir para maior competitividade, por implicar um ambiente de trabalho mais motivador e eficiente, por contribuir para uma imagem institucional positiva e por favorecer o estabelecimento de relacionamentos calcados em maior comprometimento com seus parceiros de negócio (Martinelli, 1997).

No meio empresarial brasileiro, a discussão sobre o papel social das empresas vem ganhando espaço crescente, embora as motivações para o exercício da responsabilidade social sejam de diferentes naturezas. Especialmente nos últimos quatro anos, tem havido uma corrida das empresas na direção de assumirem posturas socialmente responsáveis, o que implica uma necessidade de mudanças profundas em várias dimensões dos seus negócios.

O objetivo deste artigo é fornecer subsídios ao desenvolvimento e à implementação de estratégias de negócios voltadas para a responsabilidade social, no contexto brasileiro. Por meio dos resultados de vasta pesquisa bibliográfica são identificados os atributos necessários aos principais fatores organizacionais a serem considerados em uma análise da mudança de empresas em direção a uma postura socialmente responsável. Parte-se do pressuposto de que, para serem efetivas, tais mudanças devem estar alinhadas com a estratégia de negócios da organização. Para facilitar a compreensão deste alinhamento, é adotado um modelo para analisar a adequação estratégica, adaptado à implementação de estratégias com vistas à responsabilidade social. 
Na próxima seção explicam-se os métodos utilizados na pesquisa. Em seguida, descreve-se a evolução dos conceitos de responsabilidade social corporativa e de cidadania empresarial, fornecem-se evidências da relação entre desempenho social e desempenho financeiro de empresas e apresenta-se um quadro geral da responsabilidade social corporativa, no contexto brasileiro atual. As terceira e quarta seções são dedicadas a fornecer informações, conceitos e construtos, respectivamente, nas áreas de responsabilidade social e estratégia, que fundamentam e contextualizam a pesquisa. Na quinta seção, apresentam-se e discutem-se os resultados da pesquisa. Na última seção, fazem-se algumas considerações finais e levantam-se questões para futuras pesquisas.

\section{Metodologia}

Conforme mencionado, realizou-se uma pesquisa essencialmente bibliográfica. Inicialmente, conduziu-se uma investigação documental em relatórios de pesquisa do Instituto de Pesquisa Econômica Aplicada (IPEA), CEATS e GIFE, para que fossem coletadas informações sobre a atuação social das empresas no Brasil, para a devida contextualização da pesquisa.

Após revisão da literatura dos diferentes modelos dominantes para auxiliar a análise de gestão estratégica, escolheu-se um modelo integrativo de gestão estratégica, previamente desenvolvido e testado por uma das autoras que, embora não contemplasse a responsabilidade social corporativa de forma explícita, tivesse potencial de adaptação para uma orientação à responsabilidade social. Foi feita, então, uma pesquisa bibliográfica na literatura de negócios e sociedade (business and society), precisamente responsabilidade social corporativa, com vistas a detectar possíveis modelos de análise de gestão estratégica que incorporassem uma orientação para a responsabilidade social. Diante da carência de algum modelo completo, buscaram-se subsídios a respeito de características, condições e indicadores organizacionais, tecnológicos, humanos e de desempenho que fossem críticos das estratégias de negócios voltadas para responsabilidade social. No que concerne ao fator desempenho, houve uma preocupação com a relação entre desempenho social e desempenho financeiro.

Finalmente, com estes subsídios articularam-se os fatores específicos da responsabilidade social com aqueles pertinentes à gestão estratégica em um arcabouço para auxiliar a implementação de estratégias de negócios voltadas à responsabilidade social, apresentado no Quadro 1, a seguir. 
Responsabilidade Social Corporativa e Cidadania Empresarial

\section{Conceitos e Evolução}

A responsabilidade social corporativa baseia-se na noção de que as corporações possuem a obrigação de trabalhar para a melhoria do bem-estar social (Frederick, 1994). Wartick e Cochran (1985) elencam as duas premissas centrais deste conceito: (1) existe um contrato entre a organização e a sociedade, que funciona como um veículo por meio do qual o comportamento dos negócios é posto em conformidade com os objetivos da sociedade; (2) os negócios desempenham o papel de agentes morais dentro da sociedade, refletindo e reforçando seus valores.

Tal posição foi, por vezes, atacada com as seguintes justificativas: de que seria subversiva do sistema capitalista; por poder afetar os lucros da corporação; por representar um conceito essencialmente conservador, baseado em sistema econômico que negligencia as comunidades; pela falta de conhecimento e competência dos administradores para compreender os problemas sociais e tomar decisões acerca deles; e por existirem outras instituições como governo, igrejas, sindicatos e organizações sem fins lucrativos justamente para desempenhar tais funções (Friedman, 1970; Freeman e Liedtka, 1991; Jones, 1996).

O conceito de responsabilidade social corporativa (CSR1) vem sofrendo várias transições, passando por diferentes nomenclaturas: responsabilidade social corporativa (CSR2), com enfoque mais gerencial, com ênfase na gestão das relações entre empresa e sociedade; retidão social corporativa (CSR3), passando a incorporar uma ética normativa, ao propor padrões de comportamento desejáveis nas relações entre empresas e sociedade; e desempenho social corporativo (CSP), mais orientado para resultados, com foco no impacto dos negócios para a sociedade (Frederick, 1994).

Ao argumentar que as definições de CSR1, CSR2, e CSP não forneciam instrumentos para a coleta, organização e análise sistemáticas de dados de empresas, não possuindo significado claro do ponto de vista gerencial ou operacional, Clarkson (1995) propôs um quadro referencial para a análise da gestão das relações da empresa com as partes interessadas (stakeholders) - definidas por ele como pessoas ou grupos que possuem propriedade, direitos ou interesses passados, presentes ou futuros em uma organização e em suas atividades. Desta forma, ter-se-ia um modelo de mais fácil compreensão por parte dos gestores. É importante, segundo o autor, fazer a distinção entre questões relacionadas a stakeholders e questões sociais, pois as empresas gerenciam relações com stakeholders e não com a sociedade como um todo. 
Alternativamente ao conceito de responsabilidade social corporativa, surge fortemente na mídia e no meio empresarial a terminologia cidadania empresarial. Popularmente, este conceito vem sendo tratado de forma instrumental, com o objetivo de trazer vantagem competitiva às empresas (Ashley, Coutinho e Tomei, 2000). Alguns autores, no entanto, propõem que o conceito seja tratado de forma mais abrangente. Ao propor uma convergência entre os conceitos de cidadania empresarial e de responsabilidade social corporativa, Carroll $(1998,1999)$ aponta quatro faces para a cidadania empresarial: econômica, legal, ética e filantrópica. Para ser considerada uma empresa-cidadã, uma organização deveria, então, ser lucrativa, obedecer às leis, ter comportamento ético, seguindo padrões moralmente aceitos nas sociedades em que atua e praticar a filantropia, engajando-se ativamente em atos ou programas que promovam o bem-estar humano (Carroll, 1991).

Integrando o modelo de Carroll (1979) para o desempenho social corporativo e o conceito de gestão das relações com stakeholders de acordo com Clarkson (1995), Maignan (1999) propõe uma definição mais completa de cidadania empresarial: a extensão pela qual as organizações atendem às suas responsabilidades econômicas, legais, éticas e discricionárias, exigidas por seus diversos stakeholders.

Com o intuito de operacionalizar o conceito de cidadania empresarial, Davenport (2000) identificou medidas relacionadas a stakeholders para o desempenho social corporativo, com base em pesquisa conduzida com utilização da metodologia Delphi. Como resultado final, foram definidos os princípios da cidadania empresarial: o compromisso em conduzir o negócio de maneira ética, fazendo um esforço para equilibrar as necessidades de todos os stakeholders e trabalhar para a proteção do meio ambiente.

Para atingir o objetivo desta pesquisa, decidiu-se adotar uma visão convergente entre os conceitos de responsabilidade social corporativa e cidadania empresarial, conforme sugerido por Carroll (1998, 1999), Maignan (1999) e Davenport (2000). Utilizou-se o arcabouço analítico proposto pela última autora como subsídio para a identificação de atributos necessários para a implementação do que aqui se denomina responsabilidade social estratégica (Strategic Social Responsibility - SSR), ou seja, responsabilidade social alinhada à estratégia de negócios da organização.

É importante notar que das quatro dimensões definidas pelos autores para a responsabilidade social corporativa/cidadania empresarial, considera-se, nesta pesquisa, a ética como eixo central, devendo, idealmente, permear todas as outras, balizando as decisões no âmbito das organizações, aqui enxergadas como complexas redes de stakeholders. 
A ética empresarial engloba princípios e padrões morais que orientam o comportamento no mundo dos negócios. É a partir do crivo dos diferentes grupos de stakeholders que determinado comportamento será classificado como certo ou errado e ético ou antiético. Estes grupos irão influenciar a aceitação ou a rejeição das condutas de uma empresa pela sociedade em que atua (Ferrell, Fraederich e Ferrell, 2001). O comportamento considerado ético seria, então, aquele que busca equilibrar os interesses econômicos da empresa com os interesses dos stakeholders. Seria, ao mesmo tempo, distinto do comportamento egoísta e do comportamento puramente altruísta, em que os próprios interesses são sacrificados em prol de outros (Rossouw, 2001).

\section{Responsabilidade Social e Desempenho da Empresa}

Uma das maiores críticas sofridas pelos teóricos da área de business and society é a falta de comprovação de que exista uma relação direta entre a atuação socialmente responsável de uma empresa e seu desempenho econômico. Seria esta relação positiva, negativa ou inexistente? Que direção uma possível relação causal tomaria: é o desempenho social que contribui para determinar o desempenho financeiro ou vice-versa?

Os argumentos a favor de uma relação negativa defendem a idéia de que empresas socialmente responsáveis estariam em desvantagem competitiva, por incorrerem em maiores custos (Friedman, 1970). Os defensores de uma relação positiva argumentam que atitudes socialmente irresponsáveis culminarão em um aumento de custos, resultando em desvantagem competitiva (Waddock e Graves, 1997).

Com relação à direção da causalidade, dois tipos de argumentos emergem. O primeiro deles defende a idéia de que melhor desempenho financeiro pode ser uma predição para o desempenho social, por aumentar a probabilidade de existência de recursos livres, que podem ser alocados para questões sociais. O segundo tipo de argumento parte da premissa de que há correlação entre boas práticas administrativas e o desempenho social da empresa, porque a atenção dada aos domínios do desempenho social melhora as relações da empresa com seus principais grupos de stakeholders, resultando em melhor desempenho, de forma geral (Waddock e Graves, 1997).

Algumas pesquisas demonstram que tal relação existe de forma positiva. Waddock e Graves (1997), por exemplo, realizaram testes empíricos, utilizando como medida de desempenho social a classificação Kinder, Lyndenberg, Domini (KLD) de todas as empresas avaliadas pela S\&P 500 (com cinco atributos relativos a stakeholders: relações comunitárias, relações com empregados, desem- 
penho relativo ao meio ambiente, características dos produtos e tratamento de mulheres e minorias) e como medidas de desempenho financeiro retorno sobre ativos, retorno sobre patrimônio líquido e retorno sobre vendas. Os resultados da pesquisa confirmam a existência de relação positiva causal de mão dupla entre os dois desempenhos. Melhor desempenho social parece estar positivamente ligado a melhor desempenho financeiro, independentemente de qual das duas dimensões - social ou financeira - é utilizada como variável dependente.

Outra pesquisa buscou correlacionar o desempenho social e o desempenho financeiro de 67 grandes empresas norte-americanas durante um período de 11 anos (Preston e O'Bannon, 1997). Como medida de desempenho social, foi adotado o índice de reputação de empresas da revista Fortune (com três indicadores de reputação: responsabilidade comunitária e ambiental, habilidade de selecionar e reter bons profissionais e qualidade de produtos/serviços). Para avaliar o desempenho financeiro, os indicadores utilizados foram retorno sobre ativos, retorno sobre patrimônio líquido e retorno sobre investimento. Os resultados indicaram uma relação positiva entre os dois tipos de desempenho. Quanto à questão da causalidade, foram mais fortemente apoiadas as hipóteses de que o desempenho financeiro seja antecedente ou contemporâneo do desempenho social.

Com base no índice KLD (de 1991 a 1995), Tiras, Ruff e Brown (1998) conduziram um estudo para testar se os dados acerca da reputação de uma organização podem ser associados ao seu valor, representado na pesquisa pelo valor contábil líquido e pelo lucro contábil. Os dados analisados referem-se a quatro grupos de stakeholders: empregados, consumidores, meio ambiente e comunidade. No caso dos três primeiros, os coeficientes de avaliação foram significativamente maiores para empresas cotadas como boas (mais pontos fortes do que fracos) pelo índice KLD, do que para empresas ruins. Para comunidade, no entanto, o coeficiente de valor contábil líquido foi menor para empresas boas do que para as ruins. Esta exceção provavelmente foi causada por uma variação muito pequena nas classificações (apenas $2 \%$ das empresas foram classificadas como ruins nesta categoria), ou pela dependência entre as contribuições filantrópicas e a existência de fluxos de caixa livres. Isto fez com que não pudessem ser extraídas conclusões para a categoria comunidade.

Uma das idéias por trás da teoria dos stakeholders era descobrir uma maneira de integrar o econômico com o social. No entanto os pesquisadores da área parecem ainda não ter encontrado formas mais robustas de medir os efeitos para os stakeholders, de forma agregada. Os resultados de pesquisas citados acima, demonstram que os dois tipos de desempenho estão positivamente relacionados, o que indica a necessidade de se contemplar também o desempenho social na estratégia das empresas. 


\section{Responsabilidade Social Corporativa no Contexto Brasileiro}

A crescente busca por uma atuação socialmente responsável por parte das empresas no Brasil tem suas bases em diferentes motivações. Ao mesmo tempo que os consumidores se tornam mais conscientes, as informações correm mais rapidamente no mercado, podendo manchar a reputação de uma empresa em questão de segundos. Por outro lado, as empresas começam a vislumbrar também oportunidades. Algumas vêm relatando mudanças em suas relações comerciais, em função de sua atuação socialmente responsável, passando até mesmo por um aumento em seu poder de barganha com fornecedores, que não querem deixar de ter suas marcas atreladas à marca de uma empresa reconhecida como socialmente responsável pelo mercado (Coutinho, 2001).

O IPEA realizou pesquisas sobre a ação social das empresas no Brasil (empresas privadas de todos os portes). Os resultados para as regiões Sudeste, Sul e Nordeste mostram que o percentual de empresas que realizam algum tipo de ação social, desde pequenas doações eventuais, até grandes projetos bemestruturados, é maior do que se poderia imaginar: 67\%, 46\% e 55\%, respectivamente. Os montantes investidos foram de $\mathrm{R} \$ 3,5$ bilhões, $\mathrm{R} \$ 320$ milhões e $\mathrm{R} \$ 260$ milhões, que correspondem a 30\%, $7 \%$ e $4 \%$ do gasto social federal nas respectivas regiões, nos períodos estudados, excluídos os gastos com a previdência social (Peliano, 2000; IPEA, 2001).

As pesquisas realizadas pelo IPEA têm seu foco nas ações sociais das empresas direcionadas a apenas dois grupos de stakeholders - comunidade e empregados. Tais resultados não são relativos à responsabilidade social das empresas de forma mais ampla, segundo a definição aqui adotada. Vale ressaltar que a grande maioria das empresas pesquisadas não dispõe de informações sistematizadas sobre o impacto de suas ações sociais, podendo acarretar desperdício de recursos e a conseqüente redução na eficiência e eficácia das ações.

Nota-se, portanto, a necessidade de se desenvolverem instrumentos que auxiliem as empresas a exercerem sua responsabilidade social de maneira mais efetiva. Uma empresa não passa a ser socialmente responsável da noite para o dia. Tal transformação implica mudanças profundas em várias dimensões da organização. De acordo com o pressuposto central desta pesquisa, para trazerem resultados positivos, estas mudanças devem ser contempladas como parte integrante da estratégia de negócios da empresa. 


\section{Estratégia Empresarial: o Conceito de Adequação Estratégica}

Nesta pesquisa foram adotadas as definições a seguir para os conceitos de estratégia e adequação estratégica. Estratégia é uma proposição unificadora que "traz coerência e direção às ações e decisões de uma [...] organização" (Grant, 1999, p.3), especialmente para alavancar e alocar os necessários recursos para melhorar ou sustentar seu desempenho, de acordo com sua visão, considerando as condições ambientais internas e externas. "Uma estratégia boa [adequada] é aquela que neutraliza ameaças e explora oportunidades, enquanto capitaliza as forças e evita ou repara as fraquezas” (Barney, 1997, p.27).

O conceito de adequação estratégica (strategic fit) tem ocupado posição central nos modelos normativos de formulação estratégica, sendo, também, associado a melhores desempenhos por parte das empresas. O grau de adequação estratégica de uma empresa diz respeito à consistência de sua estratégia com seus ambientes interno e externo, bem como seus recursos, objetivos e valores (Hofer e Schendel apud Zajac, Kraatz e Bresser, 2000).

Venkatraman e Camillus (1984) chamam a atenção para o fato de que o conceito de adequação estratégica deva ser abordado sob uma perspectiva ampla, considerando a congruência entre um vasto conjunto de elementos. Assim, a identificação de variáveis críticas a serem ajustadas é de crucial importância. Outro ponto destacado é a forma de mensuração do conceito. Deveria ela ser tratada de maneira estática ou dinâmica? Em contexto de mudanças aceleradas é difícil imaginar o conceito de adequação estratégica em uma perspectiva estática, salvo raras exceções. A abordagem dinâmica, no entanto, traz consigo maiores dificuldades de mensuração.

Apesar da importância deste conceito, Zajac, Kraatz e Bresser (2000) argumentam que o tratamento dado a ele em estudos anteriores tem sido tradicionalmente estático. Por possuir característica multidimensional, já que as organizações enfrentam múltiplas contingências, tanto no nível organizacional, quanto no ambiental, a adequação estratégica seria um conceito de difícil mensuração, previsão e prescrição. Os autores apresentam, então, um modelo de adequação estratégica que se propõe a ser, dinâmico, multidimensional e normativo, considerando seus antecedentes e conseqüências.

Macedo-Soares (2000) desenvolveu um modelo integrativo para auxiliar análises estratégicas, baseando-se nas premissas da escola sociotécnica (Cherns, 1976), nos resultados de suas próprias pesquisas no Brasil (Macedo-Soares e Chamone, 1994; Macedo-Soares e Lucas, 1996) e nos Critérios de Excelência do Prêmio Nacional de Qualidade (FPNQ, 1996). 
No modelo em estudo, a organização é apresentada como sistema equilibrado para enfatizar a importância da congruência das variáveis em jogo para o sucesso da estratégia, com vistas à otimização do desempenho da organização (vide Figura 1). Essas variáveis são divididas em duas principais categorias: (1) variáveis principais dentro da organização; e (2) variáveis secundárias, tanto dentro quanto fora da organização, chamadas respectivamente de contingências estratégicas específicas e gerais, de acordo com Child (1987).

\section{Figura 1: Modelo para Análise Estratégica (Evolução do Modelo Macedo-Soares, 2000)}

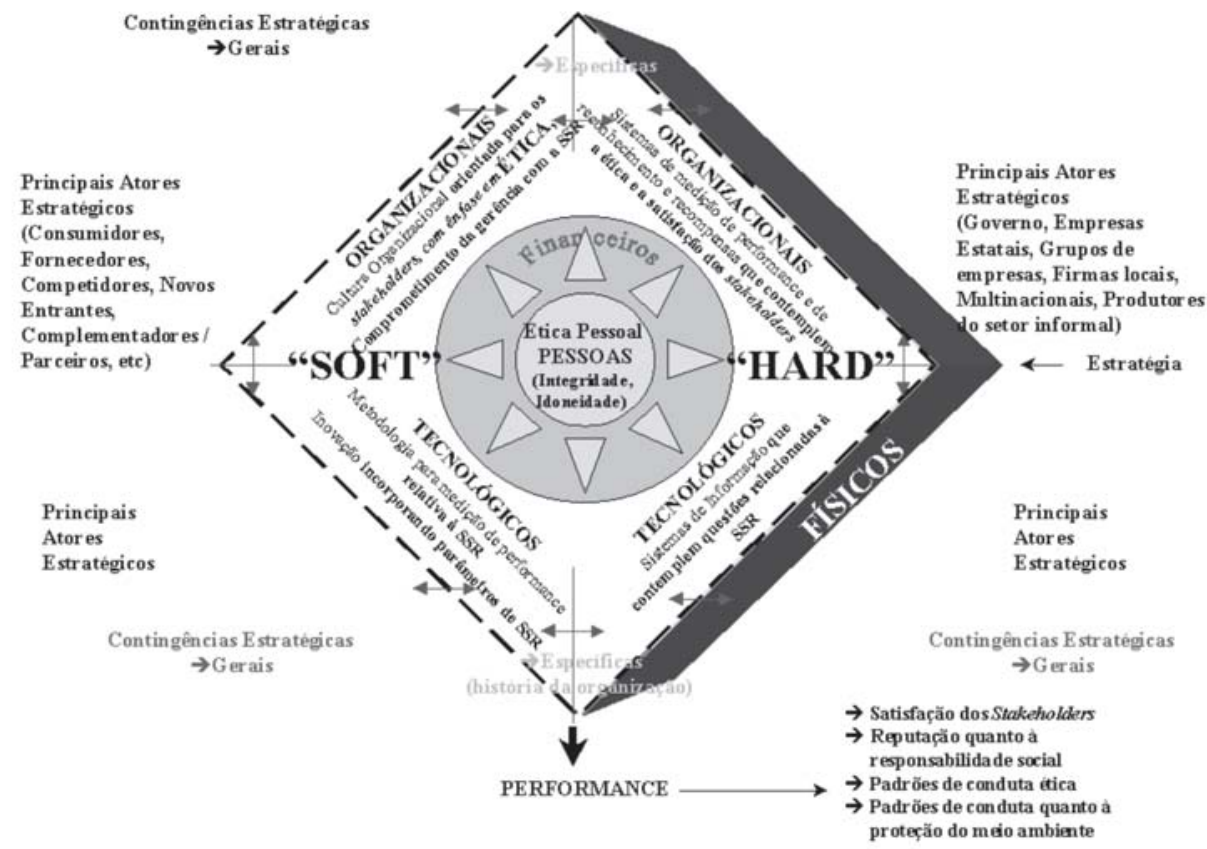

As variáveis principais são os fatores organizacionais de sucesso - recursos e condições organizacionais para alavancá-los - no sentido de serem necessárias para a otimização do desempenho da organização de acordo com suas metas estratégicas. São divididas em independentes e dependentes. As independentes referem-se aos determinantes do desempenho. São variáveis controláveis classificadas em cinco categorias de fatores: (1) pessoas, que são colocadas ao centro e, circundadas por (2) fatores financeiros, (3) fatores organizacionais, (4) fatores tecnológicos, apoiados por (5) fatores físicos. Na categoria pessoas, as variáveis relevantes são as habilidades dos indivíduos da organização - aptidões e skills -, bem como suas competências, ou seja seu conhecimento acumulado com sua experiência e suas capacidades para diferentes fins específicos (Barney, 1997). Por sua vez, as categorias organizacionais e tecnológicos incluem tan- 
to variáveis hard quanto soft. A estrutura organizacional - a estrutura de reporte formal, conforme organograma da empresa (Barney, 1997), os processos - séries de atividades inter-relacionadas que se caracterizam por séries de inputs específicos que agregam valor e produzem outputs específicos (Rummler e Brache, 1992), e os sistemas formalizados de gestão, tais como de medição do desempenho (Sink e Morris, 1995), são exemplos de variáveis hard. A cultura organizacional, no sentido de um conjunto complexo de valores, crenças, pressuposições e símbolos que definem a maneira como a empresa conduz seus negócios (Schein, 1992), a liderança, ou seja, como a alta gestão orienta a organização na definição dos valores e rumos (FPNQ, 1996), e seu comprometimento visível com eles, no sentido de colocá-los em prática no seu dia-a-dia (Sink e Morris, 1995), bem como seu estilo de tomada de decisão - participativo ou não, e a comunicação - como a alta gestão comunica os valores e diretrizes da empresa (FPNQ, 1996), são todos exemplos de variáveis organizacionais soft.

Na categoria de variáveis tecnológicas hard, cabe mencionar os sistemas de tecnologia de informações de todos os tipos, e nas soft, metodologias como para a gestão por processos de negócios - Business Process Management - BPM (Rummler e Brache, 1992) e para a avaliação do desempenho - Balanced Scorecard (Kaplan e Norton, 1992), bem como a inovação, no sentido de desenvolvimento de novos produtos e processos (Davenport, 1993).

Os recursos financeiros podem ser exemplificados pelas capacidades de geração de caixa e de financiamento da empresa. Como exemplos de recursos físicos podem ser citados equipamentos, instalações de produção, infra-estrutura e recursos naturais (Barney, 1997).

Na Figura 1, que mostra uma adaptação do modelo integrativo acima referenciado, não são representadas todas as variáveis de cada categoria. A título de ilustração, são realçadas algumas variáveis e seus respectivos atributos, pertinentes a SSR. Na categoria de variáveis organizacionais hard, por exemplo, é chamada a atenção para a importância de a ética e a satisfação dos stakeholders serem contempladas tanto pelos sistemas de medição de desempenho global da empresa quanto pelo sistema de reconhecimento e recompensa dos seus funcionários. Ao aferir o desempenho da empresa, com base nesses critérios, e ao considerá-los também como fatores de avaliação de seus empregados, para fins de reconhecimento e recompensa, a organização estará sinalizando o tipo de desempenho que almeja alcançar e os valores que gostaria de ver refletidos no comportamento de seus colaboradores. A categoria de fatores organizacionais soft é representada na figura pela cultura organizacional, que deve possuir forte ênfase em ética, retratada nos valores praticados pelos membros da organização, além de ser orientada para a satisfação de diversos grupos de stakeholders (não apenas acionistas e consumidores). As categorias de variáveis tecnológicas hard 
e soft são exemplificadas, respectivamente, pelos sistemas de informação e pela inovação e metodologias de medição de desempenho, enfatizando-se sempre parâmetros e questões relativas a SSR.

Para fins de identificação de recursos, as categorias de fatores financeiros e físicos são classificadas como recursos tangíveis, enquanto as outras são classificadas como intangíveis, por serem fortemente caracterizadas pelo componente conhecimento, mesmo no caso de possuírem componentes físicos. Estas classificações são importantes para a análise de características distintivas dos recursos da empresa, pois facilitam a identificação de diferentes categorias em que os componentes de conhecimento estão inseridos (Macedo-Soares, 2000).

Parte-se do princípio de que competências distintivas da empresa têm seu potencial de adição de valor explicado pelo fato de provirem de recursos baseados em conhecimento enraizado nos processos e sistemas organizacionais (Mahoney e Pandian, 1992). É importante ressaltar que aqui o termo competências se refere às capacidades organizacionais - e não às individuais como no caso da categoria pessoas - de acordo com o conceito de Day e Reibstein (1997).

Parte-se também da premissa de que a ambigüidade causal é a principal causa de inimitabilidade de recursos, contribuindo para que sejam distintivos (Barney, 1997) e que esta ambigüidade aumenta com a integração necessária à adequação dos recursos (Macedo-Soares, 2000). Refere-se aqui ao conceito de Diericks e Cool (1989), segundo o qual há ambigüidade causal, quando não se consegue entender como os recursos/competências de determinada empresa contribuem para a manutenção da sua vantagem competitiva.

O desempenho constitui a categoria de variáveis principais dependentes, por ser o resultado da gestão das variáveis principais independentes em interação com as variáveis secundárias. Essa categoria também inclui variáveis hard e soft, ou seja, dimensões de medição de desempenho objetivas (resultados financeiros globais, como ROA e ROI) e dimensões subjetivas (satisfação dos stakeholders, qualidade percebida do produto/serviço). Note que na Figura 1 são representadas apenas as dimensões diretamente relacionadas à SSR. Salientam-se, entre os indicadores de desempenho, reputação (positiva/negativa) quanto à responsabilidade social, (grau de) atendimento aos padrões de conduta ética definidos no código da empresa e (grau de) atendimento aos padrões de conduta, quanto à proteção do meio ambiente, que podem ser exemplificados por tratamento de efluentes, reciclagem de materiais, controle de emissão de poluentes e utilização de fontes de energia sustentáveis.

As contingências estratégicas são consideradas como variáveis secundárias, por serem fatores ambientais não controláveis que influenciam o desempenho 
das variáveis principais, por meio de suas implicações positivas e negativas. Neste sentido, podem ser consideradas oportunidades ou ameaças reais ou potenciais, a serem exploradas ou minimizadas. Inspiradas em Austin (1990), estas contingências estratégicas são classificadas em fatores ambientais econômicos, políticos, socioculturais e demográficos. Existe, no entanto, uma diferença fundamental de paradigma entre o arcabouço de Austin (1990) e o modelo de MacedoSoares (2000): Austin não distingue entre variáveis principais e secundárias dentro da empresa. Enquanto o arcabouço de Austin (1990) se inspira na escola de posicionamento, o modelo de Macedo-Soares (2000) é consistente com o seguinte pressuposto, entre outros, do paradigma resource-based: a sustentabilidade do desempenho está relacionada, principalmente, com os fatores organizacionais, precisamente com os recursos/competências distintivos e difíceis de imitar (Rumelt, Schendel e Teece, 1991). A classificação dos fatores organizacionais em variáveis principais e secundárias é relevante para a identificação dos recursos/competências distintivos. Outra diferença diz respeito aos atores estratégicos. O modelo de Macedo-Soares (2000) inclui mais um papel genérico, o do complementador (Branderburger e Nalebuff, 1997), além dos previstos por Porter (1980): concorrentes, consumidores, fornecedores, novos entrantes e substitutos.

Neste estudo, optou-se por utilizar o modelo de Macedo-Soares (2000), pois permite não só visualizar todos os fatores estrategicamente significativos, como também integrar o uso dos construtos dos outros autores mencionados, para a avaliação da adequação da estratégia que está sendo implementada por uma empresa, com vistas à responsabilidade social. Ademais, tal modelo já havia sido testado anteriormente em mais de 50 empresas atuantes no Brasil.

\section{Resultados e Discussão}

Tomando como ponto de partida o modelo mostrado na Figura 1, o arcabouço proposto por Davenport (2000) e a fundamentação teórica levantada na revisão da literatura, identificaram-se atributos e indicadores necessários, respectivamente, para cada uma das variáveis principais independentes e para as variáveis dependentes - desempenho, com vistas ao desenvolvimento e à implementação de uma estratégia de negócios orientada para a responsabilidade social. O modelo em exame também é proposto para auxiliar a análise do alinhamento destes atributos com a estratégia da empresa. Estes atributos e indicadores são apresentados como arcabouço analítico, destacando-se, em negrito, os específicos da responsabilidade social (vide Quadro 1).

O propósito do arcabouço analítico é auxiliar na confrontação das condições 
existentes na empresa para cada uma das categorias de variáveis com os atributos desejáveis para elas, conforme apresentado no Quadro 1. Os hiatos detectados para cada uma das variáveis, servirão de base para a construção de um plano de ação referente às mudanças necessárias ao atingimento da responsabilidade social estratégica, como parte do planejamento estratégico da organização. É fundamental que os objetivos de responsabilidade social estejam espelhados nas dimensões de desempenho, para que possam ser alcançados. As medidas de desempenho referentes à responsabilidade social devem ser parte integrante das medidas-chaves de desempenho global, associadas aos objetivos estratégicos. Desta forma, será possível alinhar a estratégia de negócios global da empresa com sua estratégia de responsabilidade social.

\section{Quadro 1: Arcabouço Analítico para Auxiliar a Implementação de SSR}

\begin{tabular}{|c|c|c|}
\hline Categorias de Fatores & Variável & $\begin{array}{l}\text { Atributos necessários/desejáveis à responsabilidade social } \\
\text { estratégica (strategic social responsibility - SSR) }\end{array}$ \\
\hline Pessoas & $\begin{array}{l}\text { Talentos } \\
\text { Habilidades } \\
\text { Competências } \\
\text { Ética Pessoal }\end{array}$ & $\begin{array}{l}\text { Habilidades, conhecimento e potencial para adquirir } \\
\text { as competências necessárias para a aplicação de novas } \\
\text { metodologias e práticas de SSR } \\
\text { Integridade, transparência, empatia, confiabilidade, } \\
\text { responsabilidade, idoneidade } \\
\text { Alinhamento/consistência da ética pessoal com os } \\
\text { padrões definidos no código de ética da organização }\end{array}$ \\
\hline Organizacionais Hard & $\begin{array}{l}\text { Sistema de Medição de } \\
\text { Desempenho } \\
\\
\text { Sistemas de } \\
\text { Reconhecimento e } \\
\text { Recompensas }\end{array}$ & $\begin{array}{l}\text { Flexível, horizontal, com algum grau de } \\
\text { descentralização de poder } \\
\quad \text { Multifuncionais e interfuncionais, com um bom grau de } \\
\text { empowerment } \\
\text { processos interfuncionais } \\
\text { Integrados pelos processos interfuncionais da } \\
\text { organização, com uma perspectiva socialmente } \\
\text { responsável } \\
\quad \text { Para educação contínua de gerentes e funcionários, } \\
\text { com vistas a adquirirem as competências necessárias } \\
\text { para a melhora do desempenho socialmente responsável, } \\
\text { incluindo treinamento no trabalho nas técnicas e } \\
\text { metodologias necessárias ao atingimento da SSR, com } \\
\text { ênfase em ética nos negócios } \\
\quad \text { Confiável, visível, equilibrado, compreensivo, } \\
\text { consistente e adaptável a mudanças, integrando todos os } \\
\text { subsistemas de medição e alinhado com os objetivos de } \\
\text { SSR da organização } \\
\quad \text { Avaliação de desempenho e sistemas de recompensas } \\
\text { integrados com o sistema de medição de desempenho da } \\
\text { organização, levando em consideração o comportamento } \\
\text { ético do empregado e sua contribuição para uma gestão } \\
\text { participativa e para a satisfação dos stakeholders }\end{array}$ \\
\hline Organizacionais Soft & $\begin{array}{l}\text { Liderança } \\
\text { Comunicação }\end{array}$ & $\begin{array}{l}\text { Cultura de melhoria contínua do desempenho } \\
\text { relativo à SSR, orientada para seus stakeholders, com } \\
\text { ênfase em qualidade de vida, preocupação ambiental e } \\
\text { ética. Cultura de gestão participativa } \\
\quad \text { Comprometimento visível da gerência com SSR } \\
\text { Comunicação extensiva e interfuncional, } \\
\text { favorecendo feedback constante a respeito das metas e } \\
\text { das medidas de desempenho de SSR }\end{array}$ \\
\hline
\end{tabular}




\section{Quadro 1: Arcabouço Analítico para Auxiliar a Implementação de SSR (continuação)}

\begin{tabular}{|c|c|c|}
\hline $\begin{array}{l}\text { Tecnológicos } \\
\text { Hard }\end{array}$ & $\begin{array}{l}\text { Tecnologia de } \\
\text { Informação }\end{array}$ & $\begin{array}{l}\quad \text { Sistemas de informação abrangentes, integrados e em } \\
\text { tempo real (hardware, software), que incluam informações } \\
\text { a respeito de questões relacionadas a SSR, com acesso } \\
\text { completo aos tomadores de decisão em todos os níveis } \\
\text { organizacionais }\end{array}$ \\
\hline $\begin{array}{l}\text { Tecnológicos } \\
\text { Soft }\end{array}$ & $\begin{array}{l}\text { Metodologias e } \\
\text { Técnicas Específicas } \\
\text { Inovação }\end{array}$ & $\begin{array}{l}\text { Processos de gestão interfuncionais orientados à SSR } \\
\text { Metodologia para medição de desempenho relativo à } \\
\text { SSR } \\
\quad \text { Novas soluções que incorporem requerimentos da } \\
\text { SSR } \\
\text { Desenvolvimento de novas medidas de desempenho } \\
\text { referentes a projetos inovativos de SSR, ou para fatores } \\
\text { intangíveis referentes à SSR, por ex. imagem socialmente } \\
\text { responsável, confiança, respeitabilidade, conduta ética }\end{array}$ \\
\hline Físicos & $\begin{array}{l}\text { Ativos Fixos / } \\
\text { Equipamentos / } \\
\text { Instalações de } \\
\text { Produção } \\
\text { Recursos Naturais }\end{array}$ & $\begin{array}{l}\text { Instalações e equipamentos ergonômicos, } \\
\text { propiciando qualidade de vida no trabalho } \\
\text { Instalações e equipamentos com controle de emissão } \\
\text { de resíduos } \\
\quad \text { Equipamentos com baixo nível de ruído } \\
\text { Instalações capazes de gerar produto com qualidade } \\
\text { desejada pelo cliente } \\
\text { Utilização sustentável dos recursos naturais }\end{array}$ \\
\hline Financeiros & $\begin{array}{l}\text { Geração de Caixa } \\
\text { Capacidade de } \\
\text { Financiamento }\end{array}$ & $\begin{array}{l}\text { Alta capacidade de geração de caixa para garantir } \\
\text { liquidez aos acionistas e financiar crescimento no longo } \\
\text { prazo } \\
\text {. Acesso a linhas de financiamento de baixo custo, que } \\
\text { possam ser "repassadas aos clientes" na forma de prazos de } \\
\text { pagamento mais confortáveis } \\
\text { Alocação dos recursos, considerando os interesses } \\
\text { dos diversos stakeholders } \\
\text { Honestidade na utilização dos recursos para } \\
\text { garantir a sustentabilidade dos negócios }\end{array}$ \\
\hline
\end{tabular}

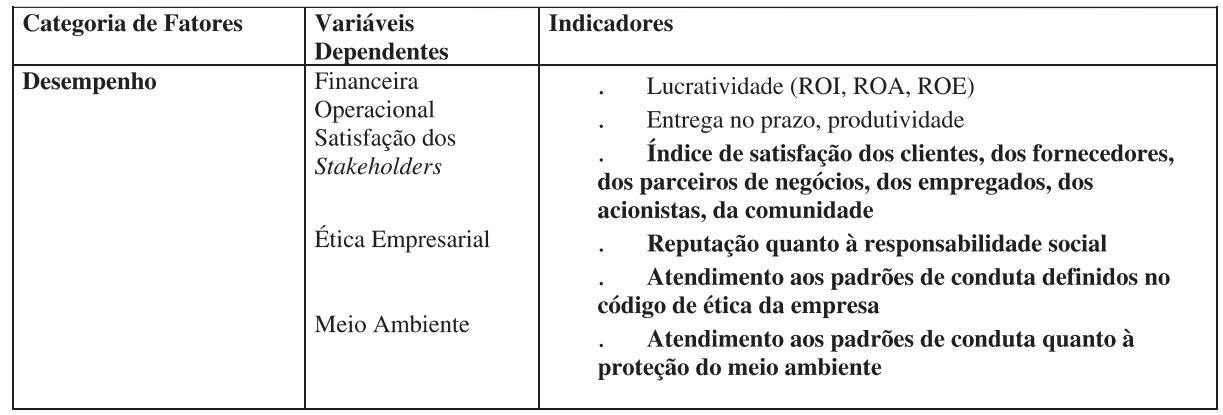

A partir da análise das variáveis principais, dependentes e independentes, aqui propostas, é possível ter uma noção da magnitude da mudança necessária, em direção à responsabilidade social. A adequação estratégica se dará por meio de mudanças nas principais variáveis independentes, para que a empresa possa aproveitar suas forças reais e potenciais (caso possua os atributos necessários), evitando suas fraquezas (caso não as tenha), para melhor explorar as oportunidades e neutralizar as ameaças ambientais, sejam elas atuais ou potenciais. Assim, a 
empresa poderá avaliar se a mudança para uma atuação socialmente responsável é realmente desejável e factível.

O instrumento apresentado pode ser utilizado para os seguintes tipos de avaliações: (a) da viabilidade e das ações necessárias para a implementação bem sucedida de uma nova estratégia; (b) das chances de sucesso de uma estratégia já iniciada; (c) das razões de insucesso de uma estratégia já implementada. Pelo fato dos questionamentos que levam a uma avaliação do tipo b serem os mais comuns no contexto atual da responsabilidade social no Brasil, em que as empresas estão começando a implementar práticas sem recorrerem a um planejamento prévio, a aplicabilidade do instrumento proposto será ilustrada com o auxílio de um exemplo para o caso deste tipo de avaliação.

\section{Aplicação do Arcabouço a um Caso Específico}

Uma empresa distribuidora de petróleo no Brasil, seguindo uma estratégia de negócios orientada para baixo custo, começou a adotar algumas medidas no sentido de uma postura socialmente responsável e se preocupava em avaliar as chances de sucesso das ações implementadas.

A sua declaração de missão e os seus objetivos já sofreram modificações. Foi elaborado um código de ética e dado início a um programa de treinamento dos funcionários, com o intuito de sensibilizá-los para a importância da responsabilidade social.

Ao confrontar as condições organizacionais existentes às necessárias para a implementação, com o auxílio da lista de referência e com base no modelo utilizado, identificaram-se várias fraquezas de natureza soft (por não possuir os atributos necessários), notadamente no que diz respeito à cultura organizacional, que poderiam comprometer o sucesso das ações tomadas em prol da responsabilidade social. Averiguou-se que, por não ter uma cultura de gestão participativa, as mudanças já efetuadas foram realizadas de forma imposta, sem a participação dos funcionários na elaboração das diretrizes e do detalhamento das práticas do código de ética, minimizando as chances de incorporação dos seus princípios e valores. Outra fraqueza identificada, que reforça a precedente, foi a falta, no sistema de avaliação e recompensa dos funcionários, de medidas referentes a uma efetiva gestão participativa (no caso da gerência), bem como referentes ao atendimento dos padrões de conduta definidos no código de ética, uma vez que tais medidas constituem impulsionadores necessários à mudança de comportamento dos funcionários e, assim, da cultura organizacional, na direção da respon- 
sabilidade social. A presença destes critérios no sistema de avaliação sinalizaria aquilo que é realmente valorizado.

Com o auxílio do arcabouço proposto, associado ao modelo adotado, a análise permitiu concluir que seriam necessárias mudanças prévias, para que pudessem ser implantadas mudanças específicas de responsabilidade social. Seria preciso realizar uma mudança de paradigma cultural e gerencial, não apenas a inclusão de intenções socialmente responsáveis na sua atual estratégia de negócios. Assim, a análise levou ao questionamento da adequação da própria estratégia ao objetivo de adotar uma postura socialmente responsável.

\section{Conclusões}

Este artigo teve como objetivo fornecer subsídios ao desenvolvimento e à implementação de estratégias de negócios orientadas para a responsabilidade social.

As pesquisas citadas demonstram que as empresas brasileiras investem mais do que se pensa na área social. Ao mesmo tempo indicam que tais investimentos são geralmente isolados, ou seja, não alinhados com suas estratégias de negócios. A corrida em direção à responsabilidade social empresarial vem sendo incentivada por pressões de diversas naturezas. Sem dúvida alguma, é um movimento que tende a trazer grandes benefícios sociais. No entanto, se desencadeado de maneira não planejada, pode ser danoso à imagem das empresas, na medida em que cria expectativas por parte dos diversos grupos de stakeholders. É preciso, portanto, que a investida no caminho da responsabilidade social seja pensada em consonância com a estratégia global da organização. Aliás, em casos como o exemplo apresentado, seria primordial a empresa começar por trabalhar uma mudança de valores, buscando uma cultura que preconize a qualidade de vida e a participação, passando, posteriormente, a uma mudança no sentido da responsabilidade social, de forma abrangente e estratégica.

Ao efetuarem a análise proposta neste artigo, dentro de uma perspectiva de adequação estratégica dinâmica de mudanças, com a utilização do arcabouço proposto, as empresas poderão dimensionar a magnitude da mudança necessária ao alcance da responsabilidade social. Tais resultados devem ser utilizados como base para o seu planejamento estratégico global.

Sob a perspectiva da adequação estratégica surgem os seguintes questionamentos: Será que toda estratégia de negócios é adequável ao exercício da responsabilidade social? Talvez, para certos tipos de estratégia, as adequações necessárias sejam 
de tal magnitude, que se chega a questionar uma mudança na maneira como a empresa se posiciona estrategicamente. Será que algumas estratégias de negócios chegam a ser incompatíveis com a responsabilidade social?

Como devem proceder as empresas que atuam globalmente? Como equacionar sua responsabilidade social no âmbito global com as divergências em padrões culturais e morais ao redor do mundo? Caso optem por perseguir diferentes estratégias de negócios em suas diversas operações, como manter coerência com relação à responsabilidade social?

Considerando o fato de que as empresas estão atuando mais e mais em redes de relacionamentos estratégicas, notadamente alianças, em que a importância de alinhar a responsabilidade social corporativa às estratégias das diferentes empresas parceiras se torna ainda mais crítica e complexa, surge mais uma questão crítica, que merece ser investigada: Como assegurar uma adequação estratégica dinâmica de empresas cujas culturas distintas influenciam suas orientações para a responsabilidade social?

As questões acima são sugeridas como pontos de partida para futuras pesquisas.

\section{ReferênCias Bibliográficas}

ASHLEY, P. A.;

COUTINHO, R. B. G.;

TOMEI, P. A.

Responsabilidade social corporativa e cidadania empresarial: uma análise conceitual comparativa. In: ENCONTRO ANUAL DA ANPAD, 24., 2000, Florianópolis.

Anais... Florianópolis: ANPAD, 2000. 1 CD-ROM.

AUSTIN, J. E.

Managing in developing countries: strategic analysis and operating techniques. New York: The Free Press, 1990.
BARNEY, J. B.

Gaining and sustaining competitive advantage. Reading, MA: Addison-Wesley, 1997.

BRANDENBURGER, A. M.; NALEBUFF, B. J.

Co-opetition. New York: Doubleday, 1997.

CARROLL, A. B.

A three-dimensional conceptual model of corporate performance. Academy of Management Review, v. 4, p. 497-505, 1979. 
The pyramid of corporate social responsibility: toward the moral management of organizational stakeholders.

Business

Horizons, v. 34, n. 4, p.39-48, 1991.

The four faces of corporate citizenship. Business and Society Review, n. 100-101, p. 1-7, Winter 1998.

Corporate social responsibility: evolution of a definitional construct.

Business and Society, v. 8, n.3, p. 268-295, 1999.

\section{CHERNS, A. B.}

The principles of socio-technical design. Human Relations, v. 29, p. 783-792, 1976.

\section{CHILD, J}

Organizational design for advanced manufacturing technology. In: WALL, T. D.; CLEGG, C. W.; KEMP, N. J. (Eds.). The human side of advanced manufacturing technology. New York: John Wiley \& Sons, 1987. p. 101-133.

CLARKSON, M. B. E.

A stakeholder framework for analyzing and evaluating corporate social performance. Academy of Management Review, v. 20, n. 1, p. 92-117, Jan. 1995.
COUTINHO, R. B. G.

Responsabilidade social corporativa no Brasil: o caso da DPaschoal Automotiva. Rio de Janeiro, 2001. Dissertação (Mestrado em Administração) Instituto de Administração e Gerência, Pontifícia Universidade Católica do Rio de Janeiro.

DAVENPORT, $\mathrm{K}$.

Corporate citizenship: a stakeholder approach for defining corporate social performance and identifying measures for assessing it. Business and Society, v. 39, n. 2, p. 210-219, 2000.

DAVENPORT, T. H.

Process innovation: reengineering work through information technology. Boston: Harvard Business School Press, 1993.

DAY, G. S.;

REIBSTEIN, D. J.;

GUNTHER, R. (Eds).

Wharton on dynamic competitive strategy. New York: John Wiley \& Sons, 1997.

DIERICKS, I.;

COOL, K.

Asset stock accumulation and sustainability of competitive advantage. Management Science, v. 35, p. 1504-1511, 1989. 
FERRELL, O. C.;

FRAEDERICH, J.;

FERRELL, L.

Ética empresarial: dilemas, tomadas de decisão e casos. Rio de Janeiro: Reichman \& Affonso, 2001.

FREDERICK, W. C.

From CSR1 to CSR2. Business and Society, v. 33, n. 2, p.150164, 1994.

FREEMAN, E.;

LIEDTKA, J.

Corporate social responsibility: a critical approach. Business Horizons, v. 34, n. 4, p. 92-97, 1991.

\section{FRIEDMAN, M.}

The social responsibility of business is to increase its profits. New York Times Magazine, 13 Sept. 1970.

FUNDAÇÃO PARA O PRÊMIO NACIONAL DA QUALIDADE.

Critérios de excelência. São Paulo: [s.n.], 1996.

GRANT, R. M.

Contemporary strategy analysis: concepts, techniques, applications. Oxford: Blackwell, 1999.

IPEA.

A iniciativa privada e o espírito público: a ação social das empresas privadas. Resultados para as regiões Sudeste, Nordeste e Sul, maio 2001.

JONES, M. T.

Missing the forest for the trees: a critique of the social responsibility concept and discourse. Business and Society, v. 35, n. 1, p. 7-41, 1996.

KAPLAN, R. S.; NORTON, D. P.

The balanced scorecard: measures that drive performance. Harvard Business Review, p. 71-79, Jan./Feb. 1992.

MACEDO-SOARES, T. D. L. V. A. An integrative model for strategic management analysis: application to organizations in Brazil. In: I N F O R M S - K O R M S CONFERENCE, Seoul, 2000. Proceedings... Seoul: [s.n.], 2000. p. 460-467.

MACEDO-SOARES, T. D. L. V. A.; CHAMONE, S. G.

Total quality strategies in industry: the experience of two multinationals in Brazil. Quality Management Journal, v. 1, n. 3, p. 57-79, 1994.

MACEDO-SOARES, T. D. L. V. A.; LUCAS, D. C.

Práticas gerenciais de qualidade das empresas líderes no Brasil. Rio de Janeiro: Qualitymark, 1996. 
MAHONEY, J. T.;

PANDIAN, J. R.

The resource-based view within the conversation of strategic management. Strategic Management Journal, v. 13, p. 363-380, 1992.

MAIGNAN, I.

Corporate citizenship: cultural antecedents and business benefits. Academy of Marketing Science, v. 27, n. 4, Fall 1999.

\section{MARTINELLI, A. C.}

Empresa-cidadã: uma visão inovadora para uma ação transformadora. In: IOSCHPE, E. B. Terceiro setor: desenvolvimento social sustentado. São Paulo: Paz e Terra, 1997.

MAYNARD JR., H. B.; MEHRTENS, S. E.

Redefinições da prosperidade empresarial. In: RAY, M.; RINZLER, A. (Orgs.). O novo paradigma nos negócios. São Paulo: Cultrix, 1993.

PELIANO, A. M. T. M. (Coord.). A iniciativa privada e o espírito público: um retrato da ação social das empresas do sudeste brasileiro. Disponível em: <http:// www.ipea.gov.br $>$ Acesso em: mar. 2000.
PORTER, M.

Competitive strategy. New York: The Free Press, 1980.

PRESTON, L. E.;

O'BANNON, D. P.

The corporate social-financial relationship: typology and analysis.

Business and Society, v. 36, n.

4, p. 419, 1997.

ROSSOUW, G. J.

The scope of business ethics.

South African Journal of Philosophy, v. 20 n. 3, p. 257-269, 2001.

RUMELT, R. P.;

SCHENDEL, D.;

TEECE, D.

Strategic management and economics.

Strategic

Management Journal, v. 12, p.

5-30, Winter 1991.

RUMMLER, G. A.; BRACHE, A. P.

Melhores desempenhos das empresas. São Paulo: Makron Books, 1992.

SCHEIN, E. H.

Organizational culture and leadership. San Francisco, CA: Jossey-Bass, 1992.

SINK, D. S.;

MORRIS, W. T.

By what method? Atlanta: Institute of Industrial Engineers Press, 1995. 
TIRAS, S.;

RUFF, B.;

BROWN, R. M.

The relation between stakeholders' implicit claims and firm value. Disponível em: $<$ http://www.ssrn.com> Acesso em: set. 1998.

VENKATRAMAN, N.;

CAMILLUS, J. C.

Exploring the concept of 'fit' in strategic management. Academy of Management Review, v. 9, p. 513-525, 1984.

WADDOCK. S. A.;

GRAVES, S. B.

The corporate social performance: financial performance link.
Strategic Management

Journal, v. 18, n. 4, p. 303-319, 1997.

WARTICK, S. L.;

COCHRAN, P. L.

The evolution of the corporate social performance model. Academy of Management Review, v. 10, n. 4, p. 758-769, 1985.

ZAJAC, E. J.;

KRAATZ, M. S.;

BRESSER, R. K.

F. Modeling the dynamics of strategic fit: a normative approach to strategic change. Strategic Management Journal, v. 21, p. 429-453, 2000. 